\title{
Level of Activity Daily Living in Post Stroke Patients
}

\author{
Greesea Dinamaria Whitiana, ${ }^{1}$ Vitriana, ${ }^{2}$ Aih Cahyani ${ }^{3}$ \\ ${ }^{1}$ Faculty of Medicine Universitas Padjadjaran, ${ }^{2}$ Department of Physical Medicine and \\ Rehabilitation, Faculty of Medicine, Universitas Padjadjaran/Dr. Hasan Sadikin General Hospital, \\ Bandung, Indonesia , ${ }^{3}$ Department of Neurology Faculty of Medicine Universitas Padjadjaran/Dr. \\ Hasan Sadikin General Hospital Bandung
}

\begin{abstract}
Background: Stroke is the leading cause of disability and dependency which directly decrease patient'slife quality . Disability caused by stroke can be prevented by holistic and comprehensive management plan of stroke. Until now, there was no study conducted to evaluate management for post stroke patients in Dr. Hasan Sadikin General Hospital (RSHS). Therefore, this studyaimed to describe level of activities of daily living (ADL) in post stroke patients in Neurology unit of RSHS as a basic evaluation for a better management hereafter.

Methods: This descriptive quantitative study participated by 31 post-stroke outpatients in Neurology Policlinic of RSHS was conducted from September to October 2015. Interviews were done to assess level of ADL by the Barthel Index score. Variables correlated with ADL (age, gender, stroke type, stroke occurrence, stroke risk factors and muscle strength) were collected from medical records. Collected data was input and presented in tables.

Results: There were 19 females and 12 males with the age group of 55-64 year old (35.5\%). Most subjects had first stroke attack (71.0\%). The most common type and risk factor were ischemic stroke (83.9\%) and hypertension $(81 \%)$ respectively. Patients with a maximum score in the entire extremity muscle strength were in the range of $60-70 \%$. Out of the 31 patients, 18 (58.1\%) were classified as independent in ADL.
\end{abstract}

Conclusions: The majority of post stroke patients in the Neurology unit of RSHS wereindependent in ADL.

Keywords: Activities of daily living, disability, post stroke

\section{Introduction}

Stroke is the most common neurological disorder in the aspects of both morbidity and mortality. According to the Global Burden of Disease, Injury, and Risk Factor, stroke is the third leading cause of disability in the world. It is also the second leading cause of death in the world. ${ }^{1}$

Post stroke patients suffer from neurological deficit. Such deficits depend on the location and the size of the lesion. Post stroke neurological deficits can be motoric and/or non-motoric, however motor deficits are more common than another. ${ }^{2}$

Motor dysfunctions can limit the ability of the patient to perform daily activities and impose on him a state of dependency. Further disability will bring patient into decreased social participation/function (handicap).

Disability does not only affect the patient but also the family. The effects can be felt in different aspects of life, especially the economic and social aspects. ${ }^{3}$ This may trigger a depression, leading to a decreased patient's life quality. Disability, depression, and decrease in life quality can create a cycle in which the patient only gets worse. ${ }^{4}$ Effective management can decrease the risk of disability and recurrence in post stroke patient. Medical rehabilitation aims to restore the patient's functional abilities. ${ }^{5}$ Intervention must be suited to the patient's condition and needs while also paying close attention to his safety and comfort in the process. One indicator of poststroke patient's current condition and his rehabilitative needs is his ability to perform activities of daily living (ADL). Until now, there is no study conducted to evaluate management for post stroke patients in Dr. Hasan Sadikin General Hospital (RSHS). Therefore, this study was carried out to describe level of ADL of post stroke patients in RSHS.

Correspondence: Greesea Dinamaria Whitiana, Faculty of Medicine, Universitas Padjadjaran, Jalan Raya BandungSumedang Km.21, Jatinangor, Sumedang, Indonesia, Phone: +6281314989504 Email: greeseadinamaria@yahoo.com 


\section{Methods}

This study took a descriptive quantitative approach. Data was collected by total sampling of the study population. The population were all post stroke patients in ambulatory care unit of RSHS from September to October 2015.

The subjects were ambulatory post stroke patients in the Neurology unit of RSHS who had a stroke attack at least a week before the visit, had no other neurological conditions causing weakness of the extremities, and had no trauma causing mobilization dysfunction. Furthermore, patients with decreased level of consciousness, auditory dysfunction, aphasia, or inability to speak in Indonesian had to be accompanied by a family member that could communicate about their condition. Based on the criteria, 31 subjects were included in this study by voluntary participation.

The data was collected by interviewing the patients or patients' family members. Patients' age, gender, stroke type, stroke event, risk factors, and muscle strength were collected from the patients' medical records. Based on the previous epidemiological studies on post stroke patients, patients' age was grouped as the following: $\leq 44$ years, $45-54$ years, $55-65$ years, $65-74$ years, and $\geq 75$ years. ${ }^{6}{ }^{\text {Patients' }}$ gender was grouped into male and female. Patients' type of stroke was classified as ischemic and hemorrhagic. Ischemic stroke is caused by thrombotic emboli or hemorrhage that interrupt blood flow while hemorrhagic stroke, is characterized by a bleeding in the brain. ${ }^{7}$ Stroke event was described as first attack stroke, which was occurrence of neurologic deficit in less than 24 hours and sudden for the first time and stroke reccurence if stroke had occured for twice. Stroke reccurence was classified as stroke affecting same side (ipsilateral) and stroke affecting different side (contralateral). ${ }^{8}$ Risk factor of stroke was described as hypertension, diabetes and others (smoking, alcohol consumption, obesity, dyslipidemia, and many others). ${ }^{8}$ Patients' muscle strength was further classified according to the results of their manual muscle testing (MMT): score 0/5 was given when there was no muscle contraction, score $1 / 5$ was given when there was muscle contraction but no movement, score 2/5 was given when there was movement with minimized effect of gravity, score $3 / 5$ was given when there was movement against gravity, score $4 / 5$ was given when the extremity could hold against some resistance, and score 5/5 was given when the extremity could hold against maximum resistance. ${ }^{9}$

Interviews were done to determine Barthel Index score. The score is for obtaining a description of the patients' ADL. The patients' Barthel Index scores were further categorized into independence (score 20), slight dependence (score 12-19), moderate dependence (score 9-11), severe dependence (score 5-8), and total dependence (score $0-4) \cdot{ }^{10}$

Collected data was input and presented in tables and next analyzed. This study had been approved by the Health Research Ethics Committee of RSHS Bandung with ethical clearance number LB.04.01/A05/EC/252/ $\mathrm{VII} / 2015$.

\section{Results}

The total number of subjects involved in this

Table 1 Distribution of ADL Based on Age and Gender

\begin{tabular}{|c|c|c|c|c|c|c|}
\hline & $\begin{array}{l}\text { Independent } \\
\text { (n) }\end{array}$ & $\begin{array}{c}\text { Slight } \\
\text { Dependence (n) }\end{array}$ & $\begin{array}{c}\text { Moderate } \\
\text { Dependence } \\
\text { (n) }\end{array}$ & $\begin{array}{c}\text { Severe } \\
\text { Dependence } \\
\text { (n) }\end{array}$ & $\begin{array}{c}\text { Total } \\
\text { Dependence } \\
\text { (n) }\end{array}$ & $\begin{array}{c}\text { Total } \\
\text { (n) }\end{array}$ \\
\hline \multicolumn{7}{|l|}{ Age } \\
\hline$<44$ & 4 & 0 & 0 & 0 & 0 & 4 \\
\hline $45-54$ & 3 & 2 & 1 & 0 & 0 & 6 \\
\hline $55-64$ & 6 & 4 & 0 & 1 & 0 & 11 \\
\hline $65-74$ & 5 & 1 & 0 & 1 & 1 & 9 \\
\hline$\geq 75$ & 0 & 2 & 0 & 0 & 0 & 2 \\
\hline \multicolumn{7}{|l|}{ Gender } \\
\hline Female & 12 & 6 & 0 & 0 & 1 & 19 \\
\hline Male & 6 & 3 & 1 & 2 & 0 & 12 \\
\hline
\end{tabular}


Table 2 Distribution of ADL based on Stroke Type, Stroke Event, and Risk Factors of Stroke

\begin{tabular}{|c|c|c|c|c|c|c|}
\hline & $\begin{array}{c}\text { Independent } \\
\text { (n) }\end{array}$ & $\begin{array}{c}\text { Slight } \\
\text { Dependence } \\
\text { (n) }\end{array}$ & $\begin{array}{c}\text { Moderate } \\
\text { Dependence } \\
\text { (n) }\end{array}$ & $\begin{array}{c}\text { Severe } \\
\text { Dependence } \\
\text { (n) }\end{array}$ & $\begin{array}{c}\text { Total } \\
\text { Dependence } \\
\text { (n) }\end{array}$ & $\begin{array}{c}\text { Total } \\
\text { (n) }\end{array}$ \\
\hline \multicolumn{7}{|l|}{ Stroke Type } \\
\hline Ischemic & 14 & 8 & 1 & 2 & 1 & 26 \\
\hline Hemorrhagic & 4 & 1 & 0 & 0 & 0 & 2 \\
\hline \multicolumn{7}{|l|}{ Stroke Event } \\
\hline First Time & 14 & 5 & 1 & 1 & 1 & 22 \\
\hline $\begin{array}{l}\text { Reccurent } \\
\text { Contralateral }\end{array}$ & 2 & 3 & 0 & 1 & 0 & 6 \\
\hline $\begin{array}{l}\text { Reccurent } \\
\text { Ipsilateral }\end{array}$ & 2 & 1 & 0 & 0 & 0 & 3 \\
\hline \multicolumn{7}{|l|}{ Risk Factor } \\
\hline Hypertension & 10 & 5 & 0 & 0 & 0 & 15 \\
\hline Diabetes Melitus & 2 & 0 & 0 & 0 & 0 & 2 \\
\hline $\begin{array}{l}\text { Hypertension and } \\
\text { Diabetes Melitus }\end{array}$ & 3 & 3 & 1 & 1 & 1 & 9 \\
\hline Others & 3 & 1 & 0 & 1 & 0 & 5 \\
\hline
\end{tabular}

study were 31 . The subjects were ambulatory post stroke patients in Neurology unit, RSHS, Bandung from September to October 2015.

Based on Barthel Index score, 18 out of 31 patients were independent in ADL (Table 1). Most post stroke patients in this study were female $(61.3 \%)$ and the largest age group was the 55-64 group (35.5\%).

Ischemic stroke was the most common type of stroke (Table 2). Most post stroke patients ,whether ischemic or hemorrhagic, were classified as independent in ADL. Majority of subjects had first stroke attack. The number of dependent patients with recurrent stroke affecting different hemisphere was higher than the number of dependent patients who had first ever stroke attack or recurrent stroke attacks affecting the same side. Hypertension was found to be the most prevalent risk factor. Other risk factors included dyslipidemia, coronary heart disease, infective endocarditis, post-chemotherapy effect and hyperthyroidism.

Roughly two-thirds of the patients had good muscle strength on their right arm, left arm, right leg, and left leg. Majority patients had maximum MMT score for all extremities (60$70 \%$ ), which contributed to the high number of independent patients (Table 3).

\section{Discussion}

Age and gender are non-modifiable stroke risk factors. In this study, the largest age group was the 55-64 year old group. This age group is still considered as a part of the productive age, as such, stroke could limit productive activities due to cognitive problems. Those problems lead to decreased executive function or motoric weakness which lead to decreased extremities' function.

From this study, most of the patients were female. Previous studies have presented that stroke incidence is lower among females than males in younger age group while it is higher among females than males in older age group. Several theories implicate the role of estrogen in preventing stroke in women. ${ }^{11}$ As female in 55-64 year old age group undergo postmenopause, it could be a reason for more female suffered stroke in this study. Other characteristic risk factors among females (preeclampsia, use of oral contraceptives, menopause, hormonal therapies, obesity/ metabolic syndrome, atrial fibrillation, and migraine with aura) may need to be considered in this condition. ${ }^{12}$

Previous studies have also pointed out old age and gender of female to be factors contributing to dependence-inducing disabilities. Female patients had more depressive feeling and lower level of memory and concentration than male. These domain play a role in patients' functional outcome. In older patients, functional recovery lasted quite long. Additional disability and comorbidities 
Table 3 Distribution of ADL Based on Muscle Strength

\begin{tabular}{|c|c|c|c|c|c|c|}
\hline $\begin{array}{l}\text { Muscle } \\
\text { Strength }\end{array}$ & $\begin{array}{l}\text { Independent } \\
\text { (n) }\end{array}$ & $\begin{array}{c}\text { Slight } \\
\text { Dependence } \\
\text { (n) }\end{array}$ & $\begin{array}{c}\text { Moderate } \\
\text { Dependence } \\
\text { (n) }\end{array}$ & $\begin{array}{c}\text { Severe } \\
\text { Dependence } \\
\text { (n) }\end{array}$ & $\begin{array}{c}\text { Total } \\
\text { Dependence } \\
\text { (n) }\end{array}$ & $\begin{array}{c}\text { Total } \\
\text { (n) }\end{array}$ \\
\hline \multicolumn{7}{|l|}{ Right Arm } \\
\hline 3 & 0 & 1 & 0 & 1 & 0 & 2 \\
\hline 4 & 3 & 4 & 1 & 1 & 1 & 10 \\
\hline 5 & 15 & 4 & 0 & 0 & 0 & 19 \\
\hline \multicolumn{7}{|l|}{ Left Arm } \\
\hline 3 & 0 & 1 & 0 & 0 & 0 & 1 \\
\hline 4 & 4 & 2 & 1 & 1 & 0 & 8 \\
\hline 5 & 14 & 6 & 0 & 1 & 1 & 22 \\
\hline \multicolumn{7}{|l|}{ Rigth Leg } \\
\hline 3 & 0 & 1 & 0 & 1 & 0 & 2 \\
\hline 4 & 2 & 4 & 1 & 1 & 1 & 9 \\
\hline 5 & 16 & 4 & 0 & 0 & 0 & 20 \\
\hline \multicolumn{7}{|l|}{ Left Leg } \\
\hline 4 & 4 & 3 & 1 & 1 & 0 & 9 \\
\hline 5 & 14 & 6 & 0 & 1 & 1 & 22 \\
\hline
\end{tabular}

in older patients were also contributed to post stroke functional outcome. ${ }^{13}$ In this study, the highest number of independent patients came from the 55-64 year old age group. Besides, all patients under 44 years old were independent while all patients above 75 years old were dependent. This study revealed that there were more female post stroke patients in the Neurology unit of RSHS, Bandung, who were categorized as independent in ADL than male patients. Patients' functional abilities and rate of dependency were not only affected by non-modifiable factors, but also by modifiable factors such as the severity of the stroke, the level of muscle weakness, patients' motivation, and the effectiveness and efficiency of post stroke management in helping patients performing ADL. 8,14

The majority of patients in this study had had first stroke attack. Control visits are meant to prevent stroke recurrence and other complications. Patients with recurrent stroke affecting different sides had a higher rate of dependency compared to those whose recurrent stroke affecting the same side. Patients with recurrent stroke had worse functional disabilities compared to those who only had first stroke attack. Based on a previous study, patients with recurrent stroke affecting different hemisphere were the least independent in ADL since there were impairments in both sides of the body. ${ }^{8}$

Ischemic stroke makes up $85 \%$ of all stroke cases in the world. This study correspondingly found more cases of ischemic stroke than hemorrhagic stroke. This may be due to the high mortality rates of hemorrhagic stroke than ischemic stroke shortly after the attack. ${ }^{15}$ This study discovered 4 out of the 5 hemorrhagic stroke patients were independent $(80 \%)$ while 14 out of the 26 ischemic stroke patients were independent (54\%). Previous studies have established that functional recovery in hemorrhagic stroke patients happened faster than in ischemic stroke patients. In the first 3 months after the attack, hemorrhagic stroke patients could achieve a better functional recovery since hemorrhagic stroke's functional impairments were caused by hematoma and brain edema. After the hematoma and the edema have disappeared, brain tissue will return to its normal state and its functional recovery will occur faster compared to ischemic stroke cases. Ischemic stroke carries a higher probability of permanent damage when scar tissue has formed in the brain.16 The different recovery rates and the ability to perform ADL are not only influenced by the type of stroke but also by another factor such as the severity, which depends on the size and location of the lesion, and muscle weakness. ${ }^{14}$

The majority of patients had hypertension 
as a risk factor of stroke. Ten of all subjects even had hypertension and diabetes mellitus concurrently. Other risk factors found in this study were dyslipidemia, coronary heart disease, infective endocarditis, postchemotherapy effect and hyperthyroidism. Hypertension was the most common modifiable risk factor found among the ischemic stroke patients even though it had a stronger correlation with hemorrhagic stroke. ${ }^{17}$ It was also quite prevalent among patients with dependency. High blood pressure was associated with risk of early reccurence in ischemic stroke and also worse intracerebral edema due to hematoma expansion in hemorrhagic stroke which lead to worse outcome. ${ }^{8}$ Consequently, better hypertension management will decrease the incidence of recurrent ischemic stroke and bring patients to a better functional ability.

The possible impairments caused by stroke on the upper extremities are muscle weakness, pain, loss of sensation, decreased agility, and decreased coordination. Muscle weakness has a stronger correlation to decreased ADL performance compared to increased muscle tone, paretic grip strength, and pain. Muscle weakness is the most common and the most readily identifiable impairment in stroke patients. ${ }^{18}$ Research has shown that muscle weakness of the lower extremities is related to the walking speed, gait endurance, and balance. Muscle weakness in any extremity will affect the patient's ability to perform ADL. ${ }^{19}$ This study scored muscle strength in a 0 to 5 scale. It was established that the majority of patients had relatively good muscle strength in their extremities with scores ranging from 3 to 5 . Patients with MMT score of 3-5 could move their arms functionally. The patient was dependent on others because of spasticity, loss of sensation, decreased agility, and decreased coordination should. This study was conducted to also describe patients' ADL without taking into consideration the above-mentioned conditions. According to the previous study, the hemiparetic side was associated with patients' ability to perform activity daily living. Hand dominance is an important aspect since it is habitually crucial in performing daily activities. Weakness of the dominant hand will decrease the patient's ability to perform those activities. However, the need to use the dominant hand will result in that hand being exercised more, it has a faster recovery than the non-dominant hand..$^{20}$

In this study, there were limitations. The sample was taken from a tertiary health facility; hence the real characteristics of the real population may not be described accurately because severity of stroke in each health facility is varying. The use of other tools beside Barthel Index should also be considered. Using Barthel Index saved the time efficiently in this research but it did not assign instrumental activity daily living which required more complex function such as cognitive function in post stroke patients. Other problems of the extremities such as pain, loss of sensation, spasticity, decreased agility, and decreased coordination also have potential to decrease the patients' ability in performing ADL. Location and size of lession, severity of stroke (NIHSS scale) and depression scale also affect level of activity daily living in post stroke patients.

In conclusion, 18 of 31 poststroke patients in Neurology unit RSHS were independent. Thirteen of 31 post stroke patients are dependent. ${ }^{8}$ Majority of post stroke patients in Neurology unit RSHS have good muscle strength in all extremities, which contributing in patients' ability to perform ADL. ${ }^{8,14}$

This study might evaluate post stroke management which have been implemented by RSHS for a better management of post stroke patients in the future. This study found out 13 of 31 patients (48.9\%) of post stroke patients are still in a state of disability. This would be concern for Physical Medicine and Rehabilitation Unit of RSHS to perform management for those patients. Further studies should be done on a wider, larger population in health facilities of different levels and measure other variables that also can affect patients' ability to perform activity daily living.

\section{References}

1. Feigin VL, Forouzanfar MH, Krishnamurthi $\mathrm{R}$, Mensah GA, Connor M, Bennett DA, et al. Global and regional burden of stroke during 1990-2010: findings from the Global Burden of Disease Study 2010. Lancet.2014;383(9913):245-54.

2. Brewer L, Horgan F, Hickey A, Williams D. Stroke rehabilitation: recent advances and future therapies. QJM. 2013;106(1):11-25.

3. Di Carlo A. Human and economic burden of stroke. Age Ageing. 2009;38(1):4-5.

4. Haghgoo HA, PazukiES, Hosseini AS, Rassafiani M. Depression, activities of daily living and quality of life in patients with stroke. J Neurol Sci. 2013;328(1):87-91.

5. Staines R, Mccoy WE, Brooks D. 
Functional impairments following stroke: implications for rehabilitation. Curr Issues Cardiac Rehab Prevent. 2009;17(1):5-8.

6. Burke TA, Venketasubramanian RN. The epidemiology of stroke in the East Asian region: a literaturebased review. Int J Stroke.2006;1(4):208-15.

7. Wang J, An Z, Li B, Yang L, Tu J, Gu H, et al. Increasing stroke incidence and prevalence of risk factors in a low-income Chinese population. Neurology. 2015;84(4):37481.

8. Liu X, Lv Y, Wang B, Zhao G, Yan Y, Xu D. Prediction offunctionaloutcomeofischemic stroke patients in northwest China. Clin Neurol Neurosurg.2007;109(7):571-7.

9. Hislop H, Avers D, Brown M. Daniels and Worthingham's muscle testing: Techniques of manual examination and performance testing. 9th ed. St. Louis: Elsevier Health Sciences; 2014.

10. Kwakkel G, Veerbeek JM, Harmelingvan der Wel BC, van Wegen E, Kollen BJ. Diagnostic accuracy of the Barthel Index for measuring activities of daily living outcome after ischemic hemispheric stroke: does early poststroke timing of assessment matter? Stroke. 2011;42(2):342-6.

11. LeBrasseur NK, Sayers SP, Ouellette MM, Fielding RA. Muscle impairments and behavioral factors mediate functional limitations and disability following stroke. Phys Ther. 2006;86(10):1342-50.

12. Reeves MJ, Bushnell CD, Howard G, Gargano JW, Duncan PW, Lynch G, et al. Sex differences in stroke: epidemiology, clinical presentation, medical care, and outcomes. The Lancet Neurol. 2008;7(10):915-26.

13. Bushnell C, McCullough LD, Awad IA,
Chireau MV, Fedder WN, Furie KL, et al. Guidelines for the prevention of stroke in women a statement for healthcare professionals from the American Heart Association/American Stroke Association. Stroke. 2014;45(5):1545-88.

14. Bohannon RW. Muscle strength and muscle training after stroke. J Rehabil Med. 2007;39(1):14-20.

15. Chattopadhyay K, Douiri A, Sheldenkar A. Trends in activities of dailyliving among stroke survivors: Analysis from the South London Stroke Register. IJTRR. 2013;2(2):6-21.

16. Henriksson KM, Farahmand B, Asberg S, Edvardsson N, Terent A. Comparison of cardiovascular risk factors and survival in patients with ischemic or hemorrhagic stroke. Int J Stroke. 2012;7(4):276-81.

17. Bhalla A, Wang Y, Rudd A, Wolfe CD. Differences in outcome and predictors between ischemic and intracerebral hemorrhage The South London Stroke Register. Stroke. 2013;44(8):2174-81.

18. Harris JE, Eng JJ. Paretic upper-limb strength best explains arm activity in people with stroke. Phys Ther. 2007;87(1):88-97.

19. Kluding P, Gajewski B. Lower-extremity strength differences predict activity limitations in people with chronic stroke. Phys Ther. 2009;89(1):73-81.

20. Harris JE, Eng JJ. Individuals with the dominant hand affected following stroke demonstrate less impairment than those with the non-dominant hand affected. Neurorehabil Neural Repair. 2006;20(3):380-9. 